\title{
Joining by Compression and Expansion of (None-) Reinforced Profiles
}

\author{
Marré, M. ${ }^{1, a}$, Brosius, A. ${ }^{1, b}$ and Tekkaya, A.E. ${ }^{1, c}$ \\ ${ }^{1}$ Institute of Forming Technology and Lightweight Construction, \\ Technische Universität Dortmund, Baroper Str. 301, 44221 Dortmund, Germany \\ amichael.marre@iul.uni-dortmund.de, balexander.brosius@iul.uni-dortmund.de, \\ cerman.tekkaya@iul.uni-dortmund.de
}

Keywords: Joining by forming, assembly, electromagnetic forming, hydroforming, frame structures, aluminum.

\begin{abstract}
One major objective of the Collaborative Research Center SFB/TR10 is the flexible and competitive production of frame structures which meet the requirements of lightweight design. The development of composite extrusion by embedding continuous reinforcing elements, like e.g. steel wires, in profiles during the extrusion process illustrates one approach to fulfill these conditions. To assemble such composite profiles, joining processes and strategies have to be developed taking into account the special composite material characteristics. In addition, the flexible production of lightweight frame structures in small quantities generates more requirements on the joining technology. The feasibility of joining by forming has been carried out investigating experimentally both conventionally extruded and reinforced profiles. Therefore, joining profiles to lightweight frame structures by both expansion and compression has been examined. The necessary forming pressure for the joining by forming processes was applied to tubular workpieces by a medium (hydroforming) and by a magnetic field (electromagnetic compression). Joints have been manufactured by these two processes to transmit axial loads either by force- or form-fit.
\end{abstract}

\section{Introduction}

Traditionally, industrial joining processes, which are largely thermal, can produce high quality joints in sufficient quantities. Within the SFB/TR10 new composite materials are produced by composite extrusion and are supposed to be joint to a frame structure [1]. In conventional extrusion processes for the manufacturing of reinforced extruded profiles composite billets are used. A promising alternative is the composite extrusion of conventional billets. Here, continuous reinforcing elements like wires are embedded in the aluminum matrix during the extrusion process by use of modified porthole dies. In porthole dies, which are used for the manufacturing of hollow sections, the mandrel, which forms the inner contour of the profile, is fixed by bridges. The billet material spreads in front of the bridges and flows through the material inlets. Behind the bridges it rejoins in the welding chamber. In the described composite extrusion process the bridges are used to supply the reinforcing elements. The tools are divided into three parts: the die, the supply element, and the sealing element, see also Fig 1. The reinforcing elements are fed from the outside and are deflected inside the tool towards the extrusion direction. In the welding chamber the reinforcing elements join the aluminum alloy. In the scope of research of the SFB/TR10 different types of metallic reinforcing elements were embedded and analysed concerning the resulting properties. The experiments focused on high strength steel wires with a tensile strength of approx. $2000 \mathrm{MPa}$. In current investigations the process will be enhanced in terms of the embedding of composite wires, like $\mathrm{Al}_{2} \mathrm{O}_{3}$ fibres which are infiltrated in an aluminum matrix [2]. Nevertheless, if composite workpieces, like composite extruded aluminum profiles with embedded steel fibres, are supposed to be joined, welding processes are likely to be insufficient. Indeed, the melting temperatures of the embedding matrix (e.g. AA6060) and the reinforcing element (e.g. 1.4310) can differ significantly, making the manufacture of homogeneous joints using welding methods alone impossible. Joining by forming offers an attractive al- 
ternative solution to thermal joining because of its high potential to maintain the joint between embedding matrix and reinforcing element. In addition, special requirements on the joint design must be fulfilled to achieve the aim of the SFB/TR10, which is the low volume production of lightweight, highly stressable and stiff frame structures made of tubes or profiles.
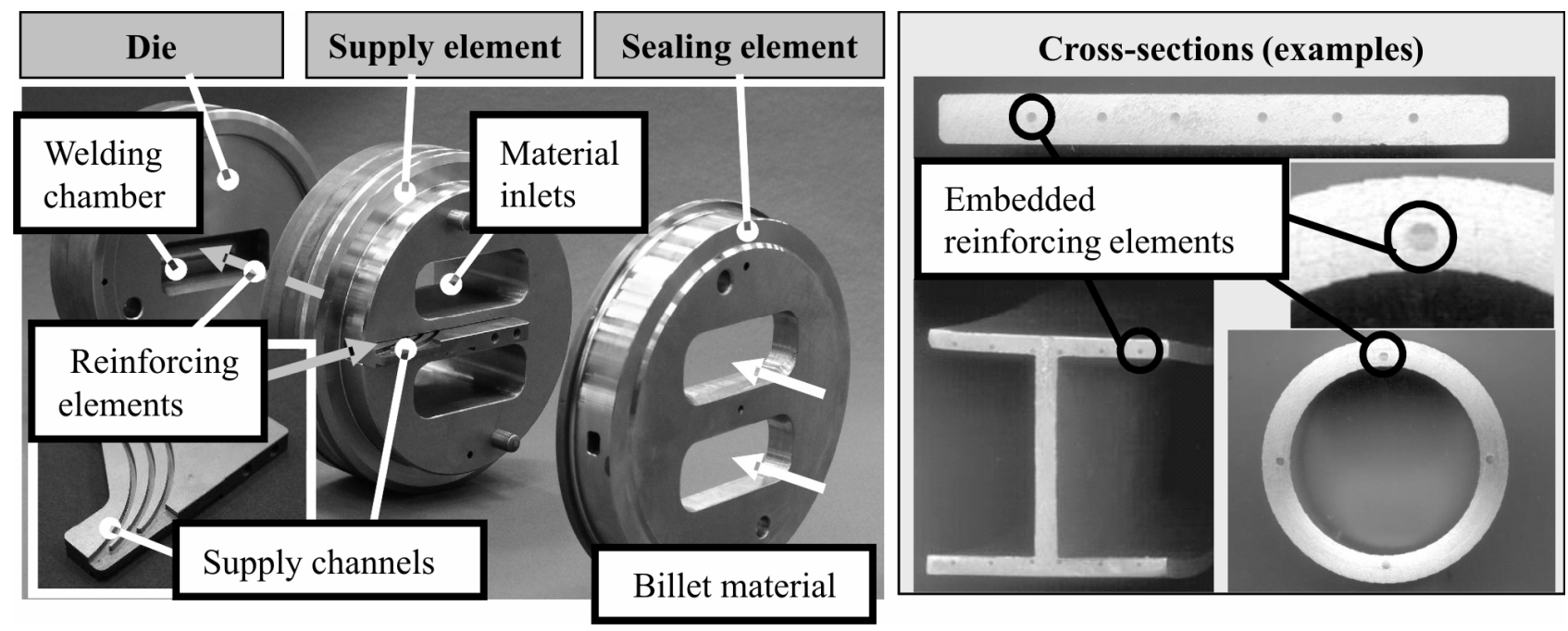

Fig. 1: Tool for composite extrusion with continuous reinforcing elements and examples of manufactured cross-sections

Therefore, a joint design must be carried out under comprehensive aspects to exclude suboptimal solutions. Furthermore, there are interacting partially conflicting requirements in the field of material characteristics, design and production engineering which have to be considered as well [3]. To achieve feasible joint designs taking pre- and post-manufacturing processes, manufacturing time, and its cost into account as well, an intense and collaborative cooperation between the projects of the SFB/TR10 is mandatory.

Generally, joints which are merely produced by forming processes are able to transmit e.g. axial loads by means of dominating force- (alternatively named as interference) or form-fit. In addition, a transmission of load could be proceeded by a combination of both mechanisms. If a very high energy is supplied, a so called magnetic pulse welded connection is producible as well by a high speed forming process [4]. This process will be neglected in the further description, as the article focuses on dominant force and form-fits. As dominating form-fit joints transmit a load partly by force-fit, the experimental investigations predominantly focussed on producing force-fit joints. Joining by compression has been done by electromagnetic forming; joining by expansion has been performed by a dieless hydroforming process.

\section{Joining by Electromagnetic Compression}

Electromagnetic forming (EMF) is a high speed process using a pulsed magnetic field to form metals with high electrical conductivity such as aluminium. Joining is the most common industrial application of the EMF-process. Due to the contact free forming process the joining of coated fuel pipes is an example of a feasible application. Furthermore, the joining of composite material as well as structural components is of an increasing interest. Especially for structural components made of aluminium alloys (with good electrical conductivity) the EMF-process is suitable and of increasing industrial interest.

Process-Principle of EMF.As the energy density of a pulsed magnetic field is used for the contactless forming of a workpiece, the resulting deformation is closely related to the electromagnetic properties. The process model (Fig. 2) can be described as an oscillating circuit which includes the capacitor $C$, the resistance $R$, and the inductance $L$ of the pulse generator as well as the consumer load consisting of tool coil and workpiece, here a solenoid and a tube. After the capacitor bank has 
been charged it is suddenly discharged by the closing of a high current switch. As a result, a damped oscillating current flows through the coil, generating a corresponding magnetic field. According to Lenz's law, a current in the workpiece will be induced flowing in the opposite direction to its cause. Due to the skin effect the current is induced on the tube's surface first. The magnetic field penetrates the workpiece wall in the course of the process' progression. The resulting pressure pulse acts orthogonally on both the field strength and the induced current, i.e. in a radial direction on tube and tool coil, as Fig. 2 shows [8].

In contrast to quasi-static forming processes, the pressure pulse in EMF causes high strain rate effects in the formed material [9]. The resulting magnetic pressure $p(t, r, z)$ is determined by the energy density of the magnetic field outside $H_{a}$ and inside $H_{i}$ of the workpiece and can be calculated on the basis of the measured coil current, displayed in Eq. 1 and described in detail in [10].

$\mathrm{p}(\mathrm{t}, \mathrm{r}, \mathrm{z})=\frac{1}{2} \cdot \mu_{0} \cdot\left(\mathrm{H}_{\mathrm{a}}^{2}(\mathrm{t}, \mathrm{r}, \mathrm{z})-\mathrm{H}_{\mathrm{i}}^{2}(\mathrm{t}, \mathrm{r}, \mathrm{z})\right)$

The calculated pressure distribution about time for the axial mid-position inside the coil is shown in Fig. 2. If the yield strength of the tube is exceeded, a permanent reduction of diameter occurs. Furthermore, a common and useful tool for forming operations by electromagnetic compression is a field concentrator or fieldshaper [9], which is placed into the gap between the tool coil and tube.

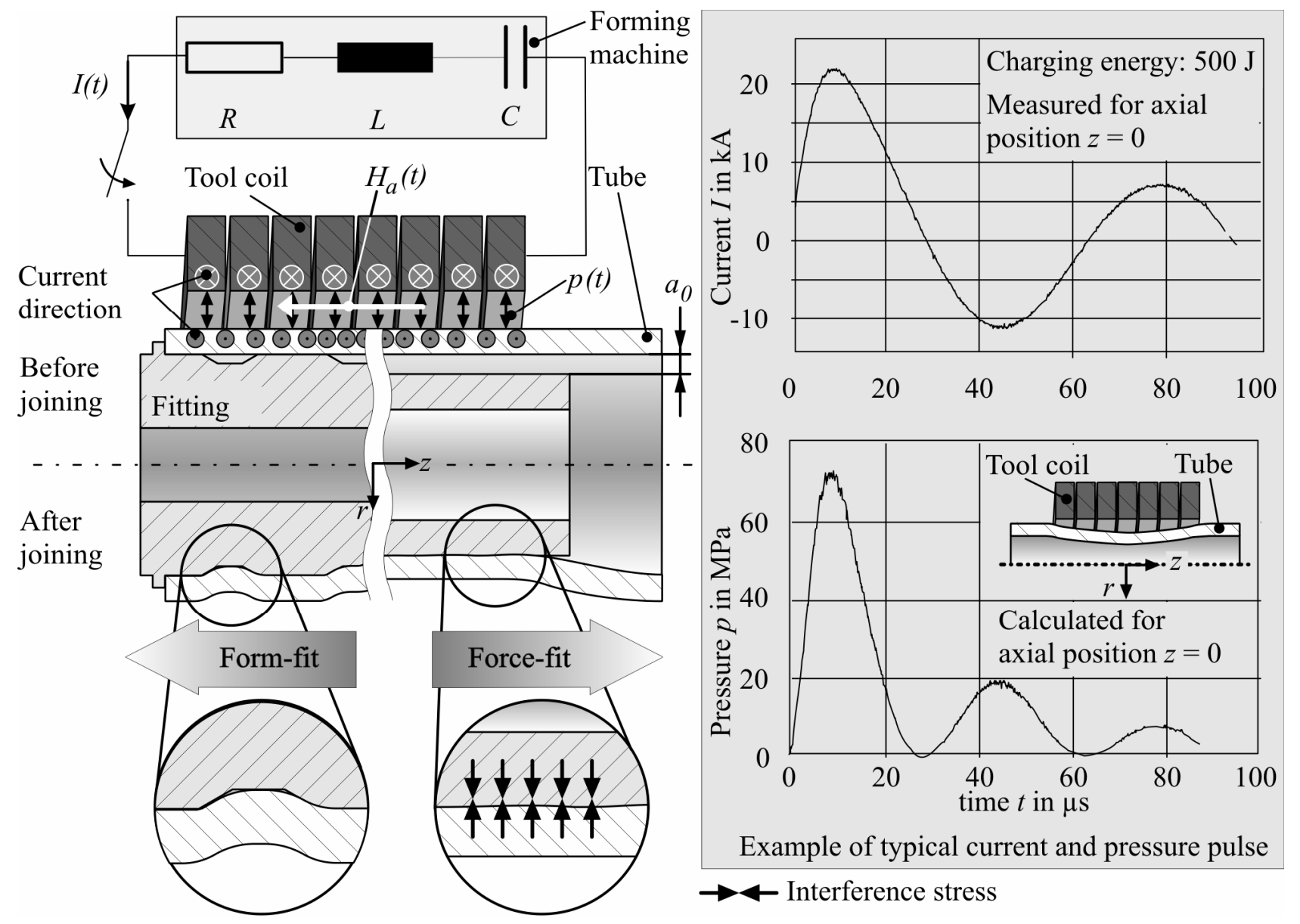

Fig. 2: Process principle of joining by electromagnetic compression with a tool coil

The purpose is, on the one hand, based on handling operations before and after forming and, on the other hand, to influence and concentrate the magnetic field's dilation respectively. In case of a setup with a fieldshaper the above described process principle is modified as follows:

Process-Principle of EMF Using a Fieldshaper. As known from the setup with a direct acting tool coil, a sudden discharge of the capacitance causes a damped sinusoidal current in the tool coil, 
which correlates to a strong magnetic field. This magnetic field induces a current in the fieldshaper. Due to the skineffect this current circulates in opposite direction to the coil current at the outer surface of the fieldshaper and in the same direction as the coil current at the inner surface of the fieldshaper (the so called concentrating area (compare Fig. 3)).

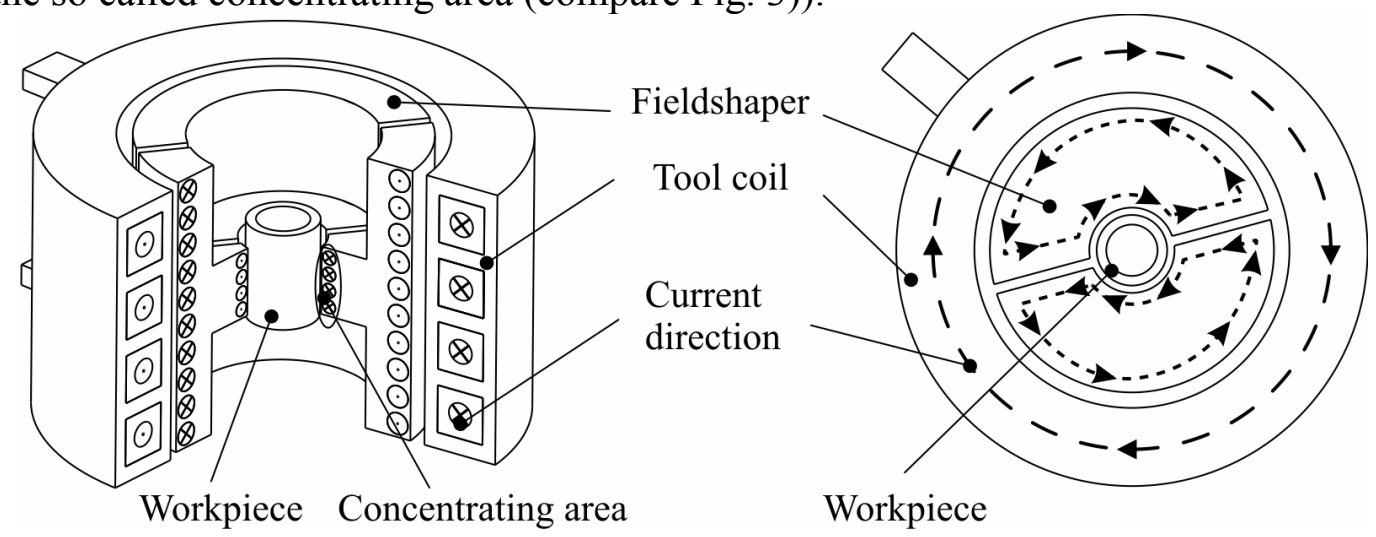

Fig. 3: Arrangement and operating mode of a fieldshaper in a toolcoil [11]

In most cases this inner surface is significantly smaller than the outer surface; therefore, the current density in this case is much higher than at the outer surface. According to the magnetic field in the gap between the fieldshaper and tube, a current is induced in the workpiece in the region of the concentrating area. If this current is closed, it shields the magnetic field. As known from the setup with a direct acting tool coil, the energy density in the gap between workpiece and tool coil is much higher than the energy density within the tube. In comparison to the setup with a direct acting tool coil, the efficiency coefficient of the process declines if a fieldshaper is used. This is evident because the extra gap volume between tube and fieldshaper has to be filled additionally with a magnetic field. Furthermore, the calculation of the course and the distribution of the magnetic field, and therefore also of the magnetic pressure, is much more complex and should therefore be performed using a simulation tool. However, the energy density again equates a magnetic pressure perpendicular to the magnetic field which causes the workpiece deformation [8].

Joints Made by EMF. In general, joints produced by electromagnetic tube compression can transmit forces by dominating force-fit or dominating form-fit. The strength of interference-fits manufactured so far is strongly depending on the area of the contact zone, the friction coefficient, and the remaining interference stress in the contact zone. While the first two aspects directly influence the strength of the joint, the last one effects the strength via material parameters like yield point and Young's modulus as well as on the geometrical stiffness of the parts to be joined [13].The constriction velocity of a tube being compressed (measured by a light shadowing method) as well as its mass determines the kinetic energy at the moment of impact and, therefore, the force which takes effect on the mandrel. Assuming a massive mandrel first, during this deformation process the tube is deformed plastically and the mandrel's deformation remains purely elastic [12]. After a decrease of the forces a corresponding elastic recovery of mandrel and tube occurs. If a full relaxation of the mandrel is prevented by the tube, a permanent pressure in the joining area (in the radial direction) is established. This pressure is a balanced condition of the mandrel's stress relief, on the one hand, and the resulting stress (caused by the elastic recovery of the mandrel) in the tube, on the other hand.

In Fig. 4, the influence of the compression velocity (determined by the charging energy) and the ratio of inner and outer mandrel's diameter on the strength of the joints are presented.

Using hollow mandrels with variable inner diameter at a constant outer diameter, the ratio of inner and outer diameter of the mandrel $Q=D_{i} / D_{a}$ has been defined as a representative value. The influence of $Q$ on the push-out force has been experimentally examined by Bühler / v. Finckenstein [14]. They identified three characteristic areas for joining a copper tube onto a steel mandrel by EMF, as displayed in Fig. 4. Recent investigations proved the transferability of these results to aluminum alloys as well [13]. 


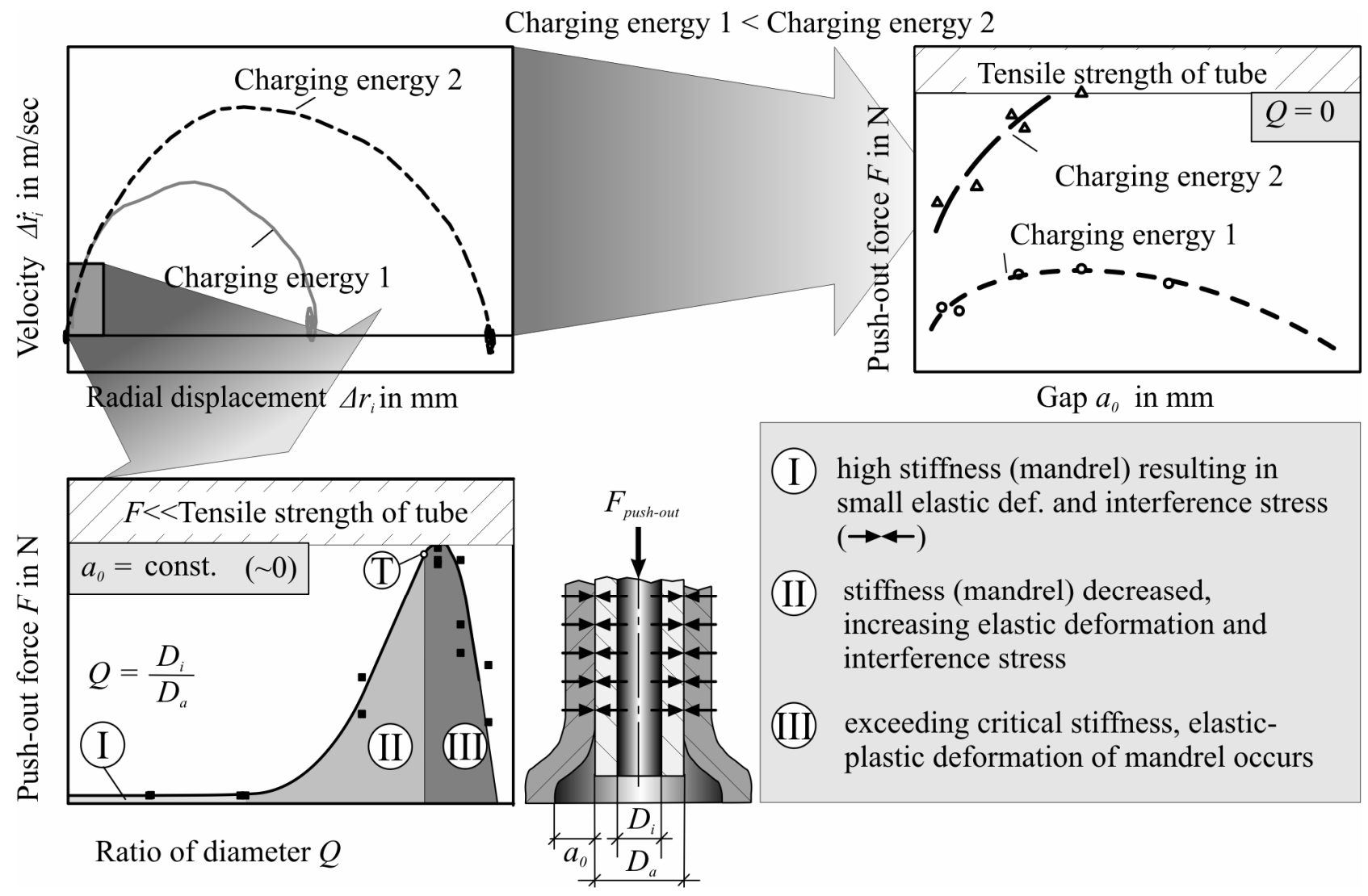

Fig. 4: Influence of the compression velocity and the ratio of inner and outer diameter on the pushout force in principle

Joining of Composite Extruded Profiles. The compression velocity (depending on the pressure pulse and the gap $a_{0}$, see Fig.4) plays a decisive role in the joining process. Selecting a suitable gap $a_{0}$ between mandrel and tube depends e.g. on an allowable diameter reduction of the tube. To determine the reduction limit of the composite extruded tubes, several composite extruded tubes of the same batch have been electromagnetically compressed. Taking the forming behaviour of composite extrudes tubes into account; an experimental setup was used consisting of a forming machine, a tool coil, fieldshaper and a composite extruded tube. This setup was used for both compressing the tube without a mandrel and for the joining process.

The charging energy, and therefore the resulting pressure pulse, was increased stepwise from sample to sample. By increasing the acting pressure pulse the resulting radial displacement was increased as well. The axial contour after forming was determined with a Zeiss coordinate measuring machine (Prismo VAST 5 HTG). As expected, an increase of the charging energy, and therefore of the pressure acting on the tube's surface, leads to a higher deformation degree of the tube. In addition, there is a slight increment of the deformed zone's length so that a clearly recognizable elongation of the tube occurs. The axial elongation of the tube causes at first a detachment of matrix and reinforcing element. Along with a continuing reduction of the diameter, necking of the reinforcing element occurs.

Fig. 5 displays micrographs made from a sectional cut in longitudinal direction of the tube's axis as well as in cross direction. Detachments as well as necking of the reinforcing element are clearly recognizable in the micrographs. Furthermore, the weld seam, which is determined by the extrusion process, is damaged by the forming process so that crack propagation is initialized. 


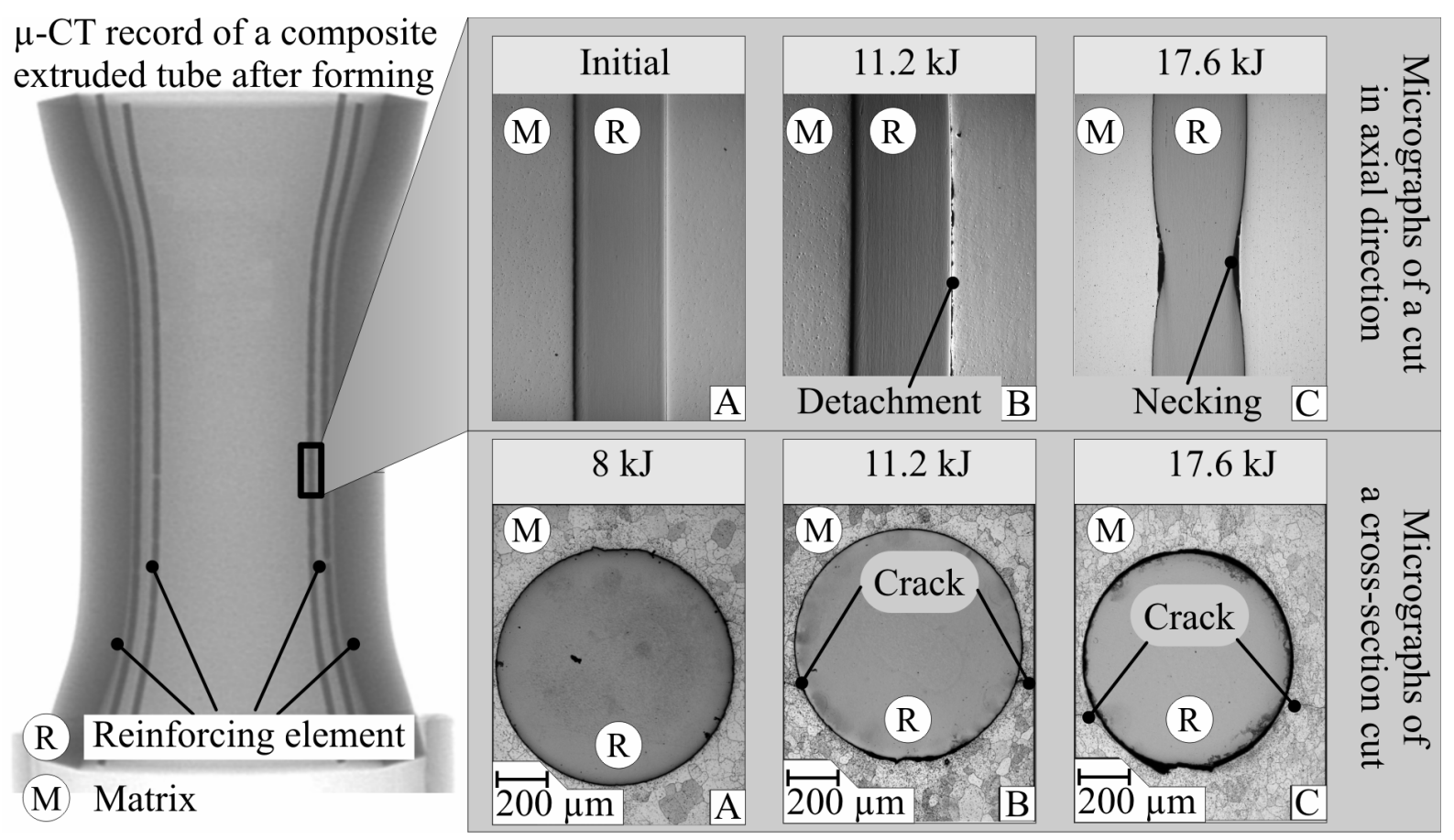

Fig. 5: Interface characteristics of matrix and tube after forming

Force-Fit Joining of Composite Extruded Tubes. Taking the above mentioned results into account, a suitable process window for joining composite extruded tubes by EMF can be deduced. Targeting a faultless interface between matrix and reinforcing element, a diameter reduction of $2 \mathrm{~mm}(7.4 \%)$ seems suitable for joining. Finally, manufacturing of common dominating form-fit joints, where the tube is formed into distinct large grooves, has to be excluded as well because of high local strain of the tubes material.

Manufacturing sufficient joints remains still possible, but an adaptation of the joining partner design is binding. Considering a feasible strength a diameter ratio of $Q=0.7$ (see Fig. 4) was manufactured $\left(D_{i}=24 \mathrm{~mm} ; D_{a}=34 \mathrm{~mm}\right)$. The parameters of the joining process were chosen guaranteeing that the inner joining partner was compressed merely elastically, which is indicated in Fig. 6.

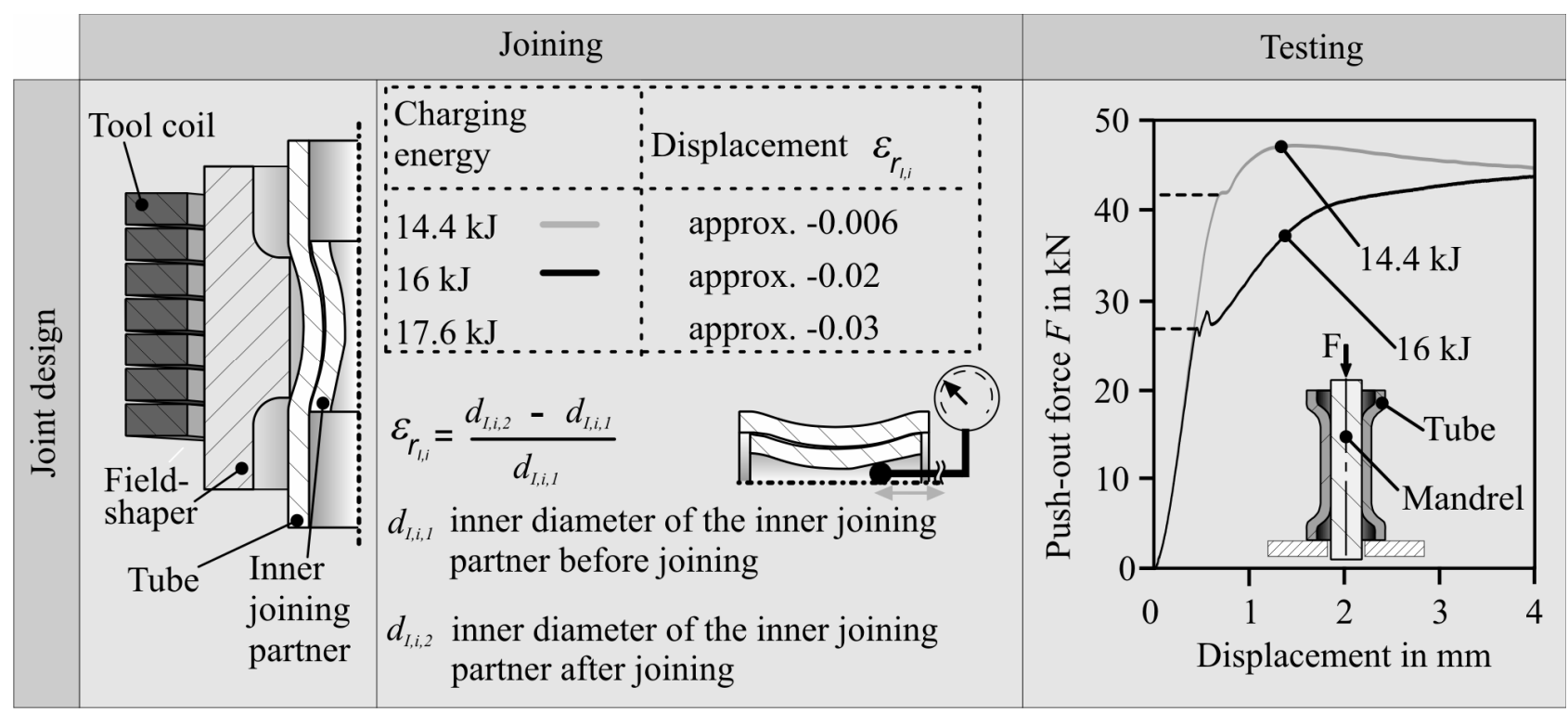

Fig. 6: Experimental results of joining and testing of an exemplarily force-fit joint with composite extruded tubes 
The joint's strength was determined on a Zwick tensile test machine by pushing out the mandrel. A maximum transferable load of $40 \mathrm{kN}$ was evaluated.

Form-Fit Joining of Composite Extruded Tubes. As discussed before, the implementation of a dominant form-fit joint by forming composite extruded tubes onto a grooved mandrel is possible, if the groove depth is adapted to the forming behaviour because of the limited allowable deformation of the composite extruded tube. Therefore, the inner joining partner was machined by cut knurling so that a rough surface with many grooves or corrugated surface respectively was manufactured. The maximal depth of the grooves was limited to $500 \mu \mathrm{m}$ so that a maximal reduction of $1.1 \%$ could occur. After that, composite extruded tubes were joined with such mandrels and tested by pushing out the mandrel. A maximum transferable load of at least $70 \mathrm{kN}$ was determined, as displayed in Fig. 7. In spite of the fact that the tube's forming velocity is very low because of the small initial gap $a_{0}$, the achievable push-out forces can be significantly improved by employing mandrels with a cut knurled surface.

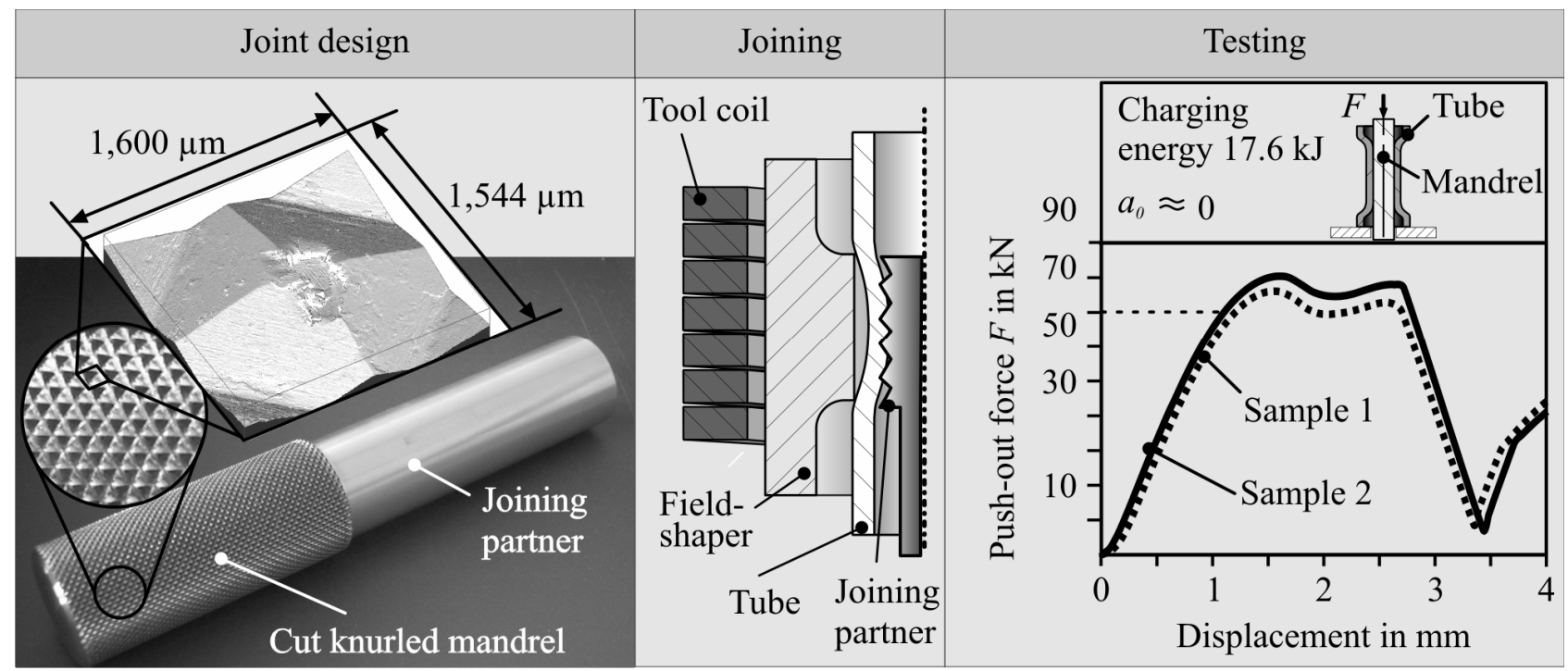

Fig. 7: Experimental results of joining and testing of cut knurled mandrels

\section{Joining by Dieless Hydroforming}

Investigations which are describing the joining by dieless hydroforming in this chapter have been done using conventional extruded tubes (without reinforcing elements) made of aluminium AA6060. Taking the process of dieless hydroforming into account, the pressure acts locally underneath a certain joining area instead of pressurizing a complete semi-finished part, as used in conventional hydroforming processes of tubes and sheet metal. The joining area is pressurized by a special joining tool, introducing it as hydro-probe. The hydro-probe is inserted into the tube, after that the working medium, which is set under pressure filles the gap between the probe and the inner surface of the tube. A sealing is limiting the joining area in circumference as well as in longitudinal direction.

Process-Principle of Joining by Hydroforming. The process of joining by dieless hydroforming can be classified into three characteristic phases, which are indicated in Fig. 8. In the first phase the tube will be expanded within the clearance's (gap's) limit, after that both parts (tube-ring) are expanding together until a maximal radial displacement is reached, which is determined by a related joining pressure (Fig. 8 a-b). The pressure ideally determines an elastic-plastic deformation of the tube, but a straight elastic deformation of the ring. Consequently, Kollmann [6] suggests for the manufacturing of shrinkage fits a maximum plastic deformation of approximately $30 \%$ concerning the total cross section of the joining partner. After releasing the pressure both tube and ring are recovering elastically. Subsequently, the elastic recovery of the ring is prevented by the expanded 
tube, as the plastic deformation remains (Fig. 8 c). Furthermore, the prevented elastic recovery of the ring results in interference fit between the joining partners (tube and ring). As known from the manufacturing of camshafts, the joining partners should be arranged with increasing yield points from the inner to the outer joining partner, if both joint partners possess the same Young's-modulus [5]. Joining of aluminum and magnesium as well as the influence of maximum expansion under pressure, ring's wall thickness, and initial gap on the joint's strength have been briefly presented in [3] and more detailed discussed taking tools and repeatability into account in [15]. From an engineering point of view the working parameters of the fluid pressure $p_{f}$ presents an important value for estimating the resulting joint's strength. According to research work performed by Garzke [5], the values of interference pressures $p$, which is the stress in the contact area of tube and ring, can be approximately computed.

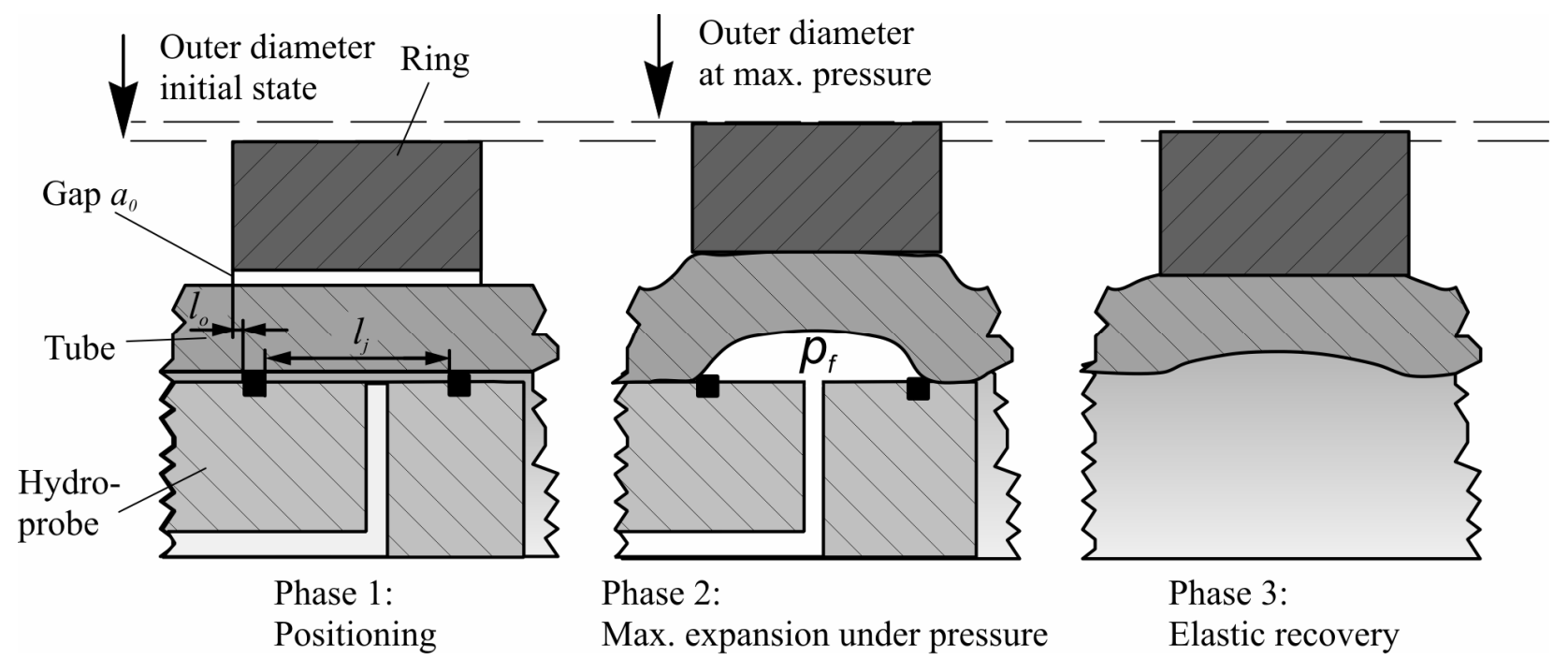

Fig. 8: Process principle of joining by dieless hydroforming

$l_{o}$ - overlapping length from O-ring to ring's front end; $l_{j}-$ length of joining area

The corresponding formula, which takes the influence of the mentioned working fluid pressure $p_{f}$ along with the joining partner design and material properties into account, is described in Eq. 2 as follows:

$p=\frac{\left[p_{f}-R_{e i} \cdot \ln \left(\frac{1}{Q_{i}}\right)\right] \cdot \frac{1}{E_{o}} \cdot\left[\frac{1+Q_{o}^{2}}{1-Q_{o}^{2}}+v_{o}\right]+\frac{2 \cdot Q_{i}^{2}}{E_{i}\left(1-Q_{i}^{2}\right)} \cdot R_{e i} \cdot \ln \left(Q_{i}\right)}{\frac{1}{E_{o}} \cdot\left[\frac{1+Q_{o}^{2}}{1-Q_{o}^{2}}+v_{o}\right]+\frac{1}{E_{i}} \cdot\left[\frac{1+Q_{i}^{2}}{1-Q_{i}^{2}}-v_{i}\right]}$.

$p \quad$ - interference pressure in $\mathrm{N} / \mathrm{mm}^{2}$,

$p_{f}$ - working fluid pressure in $\mathrm{N} / \mathrm{mm}^{2}$,

$R_{e i}$ - elastic limit of the tube material in $\mathrm{N} / \mathrm{mm}^{2}$,

$E_{i}-$ modulus of elasticity of the tube material in $\mathrm{N} / \mathrm{mm}^{2}$,

$E_{o}$ - modulus of elasticity of the ring material in $\mathrm{N} / \mathrm{mm}^{2}$, $v_{i}$ - Poisson's ratio of the tube material,

$v_{o}$ - Poisson's ratio of the ring material,

$Q_{i}$ - diameter coefficient of the tube $Q_{i}=d_{i} / d_{o}$,

$Q_{o}$ - diameter coefficient of the ring $Q_{o}=D_{i} / D_{o}$.

The calculated interference pressure $p$ is a regularly distributed, tangential mean value, which has been derivated assuming plane stress, maximum shear stress criterion, and ideal plastic material.

Force-Fit Joining of Extruded Tubes. Therefore, the real distribution of the tangential strain in the joint after the joining process could not be indicated. Furthermore, buckling of the rings occurs so that a barrel-like shape of the ring results. Experimental investigations have been carried out to detect the developing shape during the joining process and the causal tangential stress as well as its 
distribution in axial direction on the ring's surface after the joining process. Tests have been done using ARAMIS by gom, which is a non-contact optical 3D deformation measuring system. Starting with the first recorded image, which represents the initial, undeformed state of the ring ARAMIS compares following digital images and stepwise calculates the displacement and deformation of the ring. As the system operates with two independent cameras, it is particularly suitable for threedimensional deformation measurements under static and dynamic load in order to analyze deformations and strain during the joining process. Fig. 9 displays the major strain and its axial distribution after the joining process on the ring's surface.

As a result of the overlapping lenght $l_{o}$, the ring's front end, whose position is indicated as area $I$ in Fig. 9, applies a pressure radially against the tube's wall, introducing it as rim stress. Consequently, a major strain in this area is determined as negative, whereas another major strain between the O-ring sealings, indicated as area $I I$, remains positive. Subsequently, this determines some requirements for both process guiding and process design. Taking the process design into account, the length of the ring and joining length $l_{j}$ should be designed equally at best in length to avoid buckling and an unregular axial distribution of major strain as well as causal rim stress. Therefore, the overlapping length $l_{o}$ should be designed as small as possible. Consequently, process guiding has to be designed so that an accurate positioning of the hydro-probe (and therefore of the sealing) is guaranteed.
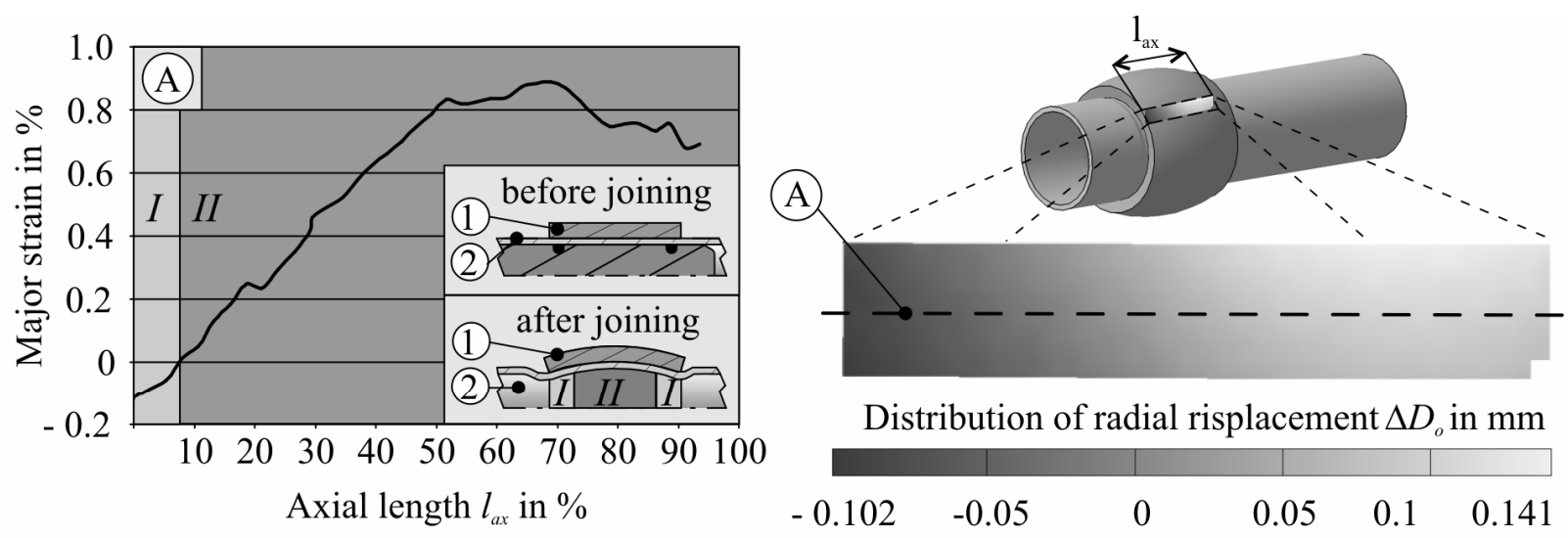

Tube: (1) Ring: (2)

Outer diameter: $40 \mathrm{~mm} \mathrm{f} 7$ Length: $160 \mathrm{~mm}$ Inner diameter: $40 \mathrm{~mm} \mathrm{H} 8$ Length: $32 \mathrm{~mm}$

Wall thickness: $2 \mathrm{~mm} \quad$ Material: AA6060 Wall thickness: $5 \mathrm{~mm}$ Material: AA6060

Fig. 9: Optically measured distribution of major strain on the ring's surface after joining

Form-Fit Joining of Extruded Tubes. Furthermore, joining could be done by forming the tube into a grooved ring. Designing feasible grooves offers a wide range of appropriate groove shapes. Basic experimental investigations have been done to carry out the influence of the groove's shape on the joint's strength. As indicated in Fig. 10, groove shapes have been manufactured according to basic geometrical layouts, which are in detail round $(\mathrm{R})$, trapezoid $(\mathrm{T})$, rectangular $(\mathrm{RE})$, and triangle or $\mathrm{v}$-shaped (V). To evaluate comparable results in terms of the joining quality, groove length, groove width, and radii of the groove's edge were machined in the same way. Moreover, process parameters like the ring's expansion during the joining process as well as the material of tube and ring were identically used for the experimental investigations.

The maximal transferable load was determined by tensile tests on a Zwick Z250. To identify the quality of the form-fit joints, the acceptable load of a cylindrical (C) force-fit joint was chosen as a reference. Consequently, the final shape of the tube section, which was formed into the groove, was investigated as well. After joining was finished, cutouts were machined to evaluate the quality of the manufactured shape of the tube's section. Both axial load and final shape are indicated in Fig. 10 in 
comparison to the groove's shape. As expected, according to the publication of Dudziak [16], small radii were not produceable by the applied pressure, which was increased during the joining process until elastic deformation of the ring occurs.

Taking the applied pressure into account, the elastic deformation of the outer ring determines a process limit for manufacturing both force- and form-fit joints. Furthermore, a pre-damaging of the tube by the manufacturing of a form-fit joint, e.g. caused by a cut of the grooves edge, was not detactable. Subsequently, taking rectangular grooves (RE) into account, resistance against axial load is dominantly caused by the form-fit. Evidently, this is due to the very small area of contact between tube and ring, as indicated by the micrograph in Fig. 10. If an axial load is applied to the joint, failure proceeds by bending or pushing of the tube's wall backwards to its initial geometry. The bending momentum is applied at the groove's edge. If the groove edge is rounded $(\mathrm{R})$ or chamfered $(\mathrm{T})$, the contact situation changes from point or line contact to an area contact situation. Consequently, slipping of the tube's wall about the grooves edge and shoulder occurs more evident, which leads to less resistance against axial load. Taking v-shaped grooves into account, a stabilization of the joint could be generated by the opposing groove's shoulder, which then leads to a higher resistance against deformation.

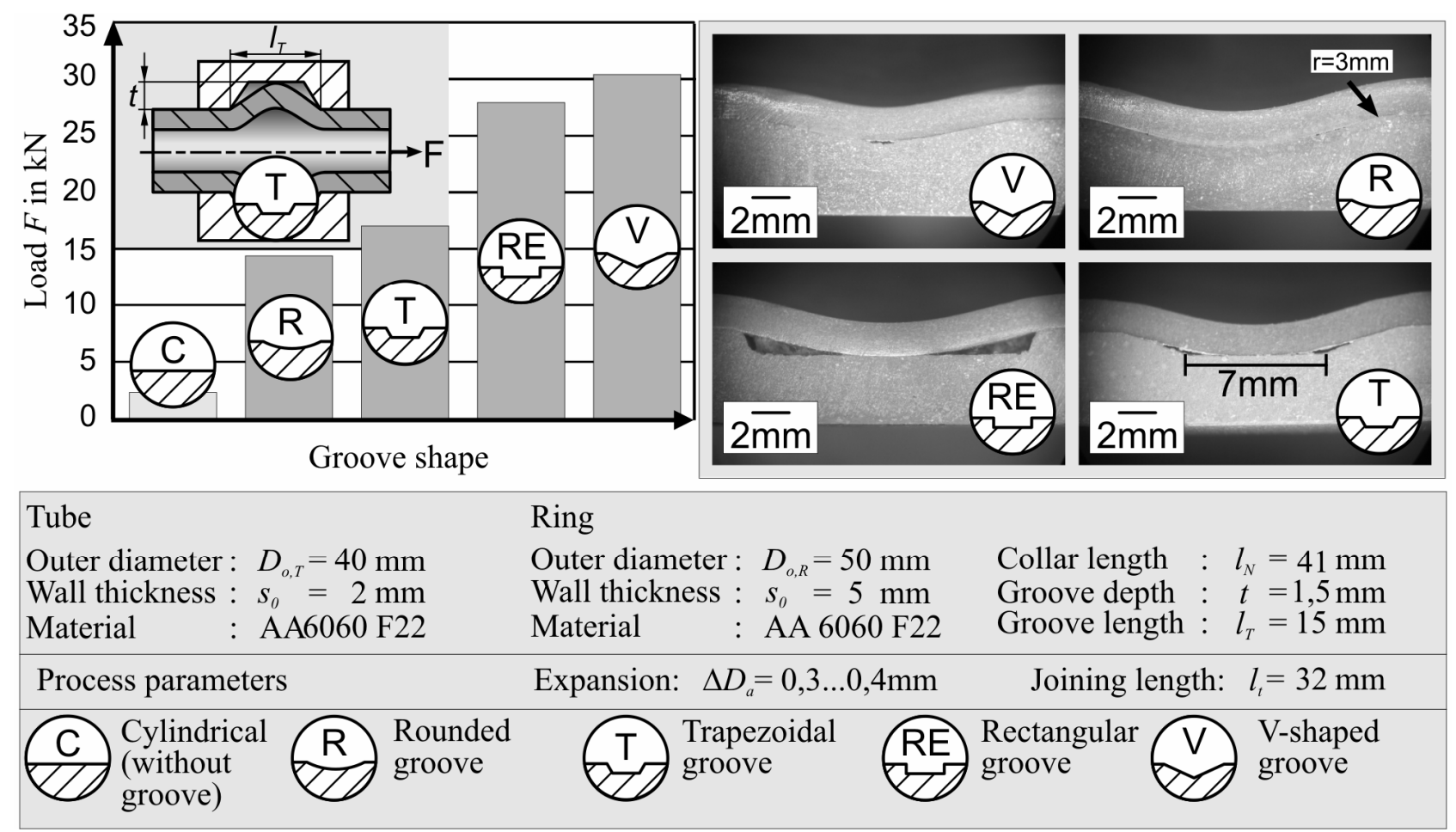

Fig. 10: Quality of form-fit joints taking different groove shapes into account

Form-fit joints are able to resist higher axial loads compared to force-fit joints. Besides the grooves geometry its shape is a major influencing factor on the joint as well. The shape determines the maximum load as well as possible points at risk from corrosion, if tube's material is not properly formed into the groove.

Taking corrosion into account tube's material is formed into rounded grooves $(\mathrm{R})$ at best, which leads to minor risk of corrosion. In addition, tube's material was not properly formed into the other investigated groove shapes. This leads to higher risk of corrosion due to gaps between the tube and the ring in which fluid e.g. water could remain after joining. As a result, corrosion proceeds in these cases from the inside to the outside. Because corrosion starts from inside the joint both appearance and development is hardly to detect. 


\section{Summary and Outlook}

In this paper, the processes of joining by compression - using an electromagnetic pulsed pressure - and by expansion - using a quasistatic high water pressure - of aluminium profiles have been described.

At first, the forming behavior of composite extruded tubes, compressed by electromagnetic forming has been analyzed, taking material characteristics e.g. the forming behaviour into account. The allowable forming limit of the composite extruded tube which is important for selecting feasible the joining parameters was finally limited by crack initiations in the profile. Furthermore, dominating force-fit and form-fit joints have been exemplarily manufactured considering the low acceptable deformation of the composite extruded tube. As a result, the pull-out forces could be increased from $40 \mathrm{kN}$ in force-fit joints to $70 \mathrm{kN}$ in form-fit joints in a first step.

Future investigations have to be conducted in the extrusion process as well as in the joining process. The composite extrusion process will be further improved in order to produce composite extruded profiles with an increased number of reinforcing elements along with a smaller wallthickness. In addition, the forming limit of composite extruded tubes has to be increased as well. Investigations on the joint design have to proceed as well. For instance, if cut knurling is used, effects on the joint under cyclic load focusing on crack initiation need to be investigated. As cutknurling is one surface for increasing the joint's strength

Thereafter, joining of tubular workpieces by dieless hydroforming seems to be feasible as well. Joints produced by this process are able to transmit high axial loads. Positioning of the tool remains a major objective for introducing this joining process into manufacturing, targeting a homogenous expansion of tube and ring. Unsuitable positioning determines inhomogeneous expansion of the ring, which leads to an irregular development of the interference stress in the contact zone between tube and ring. Furthermore, the geometric shape of the expanded ring occurs barrel-like, which has to be considered in future investigation, if parts of more geometric complexity like nodes are joined. As a major process characteristic is the very small necessary degree of deformation for producing force-fit joints, the process seems suitable for further investigations, taking the joining of composite extruded profiles into account. At present, joining of profiles without a round cross-section remains difficult due to sealing and leaking challenges related to the tool design so that further development is needed here.

Furthermore, joining of profiles with a small forming limit like the composite extruded tubes determines more investigations targeting higher resisting loads. Consequently, effects of structuring the surface in micro- as well as in macro-scale on the joints quality need to be investigated.

\section{Acknowledgements}

This paper is based on investigations of the Transregional Collaborative Research Center SFB/TR10, which is kindly supported by the German Research Foundation (DFG). 


\section{References}

[1] A. Klaus, M. Kleiner: Research for a Flexible Production of Lightweight Space Frame Structures, In: Advanced Materials Research: Flexible Manufacture of Lightweight Frame Structures, Band 10 (2006), pp. 89-100

[2] M. Kleiner, M. Schomäcker, A. Klaus: Influencing Factors on the Manufacture of Composite Extrusions, In: Annals of the German Academic Society for Production Engineering, WGP, Vol $\mathrm{XIII} / 1(2006)$

[3] W. Homberg, M. Marré, C. Beerwald, M. Kleiner: Joining by forming of lightweight frame structures, In: Advanced Materials Research: Flexible Manufacture of Lightweight Frame Structures, Band 10 (2006), pp. 89-100

[4] M. Kojima, K. Tamaki: Factors affecting the result of electromagnetic welding of aluminum tube. Transactions of the Japan Welding Society, 1953-59, 1988.

[5] M. Garzke: Auslegung innenhochdruckgefügter Pressverbindungen unter Drehmomentbelastung. Diss. TU Clausthal, VDI Verlag Düsseldorf, 2001

[6] F. Kollmann: Welle-Nabe-Verbindungen, Gestaltung, Auslegung, Auswahl, Springer Verlag Berlin (1984)

[7] M. Marré, W. Homberg, A. Brosius, M. Kleiner: Umformtechnisches Fügen In: Fortschr. Ber. VDI Reihe 2 Nr. 661, VDI-Verlag Düsseldorf, 2007, pp. 215-245

[8] F. Wilson: High Velocity Forming of Metals, A.S.T.M.E, Englewood Cliffs, USA, 1964

[9] P. Zhang, G. Daehn: Analysis of the electromagnetic impulse joining process with a field concentrator. In: Ghosh S, Jose M, Castro JM, Lee JK, editors. In: Proceedings of the eighth international conference on numerical methods in industrial forming processes, Columbus, $\mathrm{OH}$, 2004. pp. 1253-58.

[10] C. Beerwald: Grundlagen der Prozessauslegung und -gestaltung bei der elektromagnetischen Umformung. Universität Dortmund - IUL, Dr.-Ing. Diss., Reihe Umformtechnik, Shaker Verlag, Aachen 2005, ISBN 3-8322-4421-2.

[11] Schnelle Magnetische Umformung. Firmenschrift der Puls-Plasmatechnik GmbH, Dortmund, 1990

[12] P. Barreiro, V. Schulze, D. Löhe, M. Marré, C. Beerwald, W. Homberg, M. Kleiner: Strength of tubular joints made by electromagnetic compression at quasi-static and cyclic loading, In: 2nd International Conference on High Speed Forming, 20.3.-21.3.2006, Dortmund, Germany, Proceedings, pp.107 -166, ISBN 3-00-018432-5

[13] M. Kleiner, M. Marré, C. Beerwald, W. Homberg, D. Löhe, P. Barreiro, V. Schulze: Investigation of force-fit joints produced by electromagnetic tube compression, In: Annals of the German Academic Society for Production Engineering, WGP, Vol. XIII/1 (2006), pp. 227-230

[14] H. Bühler, E. von Finckenstein: Fügen durch Magnetumformung, Werkstatt und Betrieb, 101. Jahrg., Heft 9 (1968) pp. 209-215

[15] W. Przybylski, J. Wojciechowski, M. Marré, M. Kleiner: Archives of Mechanical Technology and Automation, Vol.27 Nr. 1, Polish Academy of Science, 2007, S. 152-167 ISSN 1233-9709

[16] K.-U. Dudziak: Prozessmodell zum Innenhochdruckumformen von hohlwellenförmigen Werkstücken, Fortschrittsberichte VDI, Reihe 2, Nr.368 VDI Verlag GmbH, Dissertation Universität Paderborn (1996) 